\title{
Vaccarin alleviates hypertension and nephropathy in renovascular hypertensive rats
}

\author{
WEIWEI CAI* ${ }^{*}$, ZHENPENG ZHANG* ${ }^{*}$ YIQI HUANG, HAIJIAN SUN and LIYING QIU \\ Department of Basic Medicine, Wuxi School of Medicine, Jiangnan University, Wuxi, Jiangsu 214122, P.R. China
}

Received June 7, 2017; Accepted November 2, 2017

DOI: $10.3892 /$ etm.2017.5442

\begin{abstract}
The kidney is an important organ in the regulation of blood pressure, and it is also one of the primary target organs of hypertension. Kidney damage in response to hypertension eventually leads to renal insufficiency. The authors previously demonstrated that vaccarin exhibits a protective role in endothelial injury. However, the effects of vaccarin on the two-kidney, one clip (2K1C) renovascular hypertension model and subsequent kidney injury have yet to be fully elucidated. The present study was designed to investigate the roles and mechanisms of vaccarin in attenuating hypertension and whether vaccarin had beneficial effects on kidney injury. The $2 \mathrm{~K} 1 \mathrm{C}$ rats had greater fibrosis, apoptosis, reactive oxygen species production, inflammation, angiotensin II (Ang II) and angiotensin type 1 (AT1) receptors in the right kidney compared with normotensive rats, which were alleviated by a high dose of vaccarin and captopril. Vaccarin treatment attenuated hypertension, reduced fibrosis markers, NADPH oxidase (NOX)-2, NOX-4, 3-nitrotyrosine, tumor necrosis factor- $\alpha$, interleukin $1 \beta$ (IL-1 $\beta$ ), and IL-6 protein levels and altered pro-apoptotic protein levels including caspase-3, anti-apoptosis protein B cell lymphoma (Bcl)-2 and Bcl-2 associated $\mathrm{X}$, apoptosis regulator in the right kidney of $2 \mathrm{~K} 1 \mathrm{C}$ rats. These findings suggest that the protective effects of vaccarin on the right kidney in renovascular hypertension are possibly due to downregulation of fibrosis, inflammatory molecules, oxidative stress, Ang II, and AT1 receptor levels.
\end{abstract}

\section{Introduction}

Hypertension is believed to be a major reason of people deaths caused by cardiovascular diseases, which is largely responsible

Correspondence to: Dr Haijian Sun or Professor Liying Qiu, Department of Basic Medicine, Wuxi School of Medicine, Jiangnan University, 1800 Lihu Avenue, Wuxi, Jiangsu 214122, P.R. China

E-mail: haijsunjiangnan@jiangnan.edu.cn

E-mail: qiulydoc@163.com

${ }^{*}$ Contributed equally

Key words: hypertension, oxidative stress, inflammation, fibrosis, renal injury for chronic kidney injury and end-stage renal disease (1). Multiple therapeutic choices may slow down the development and progression of hypertensive nephropathy, a large number of hypertensive patients are still ultimately suffering to end-stage renal disease (2). The deoxycorticosterone acetate or high-salt diet-induced hypertension is associated with amplification of renal injury in Goto Kakizaki (GK) rats (3). Renal impairment is a frequent problem in cardiovascular diseases including hypertension (4). The destructive renal function contributes to tubular interstitial fibrosis, vascular sclerosis and glomerular sclerosis (5). Activation of renin-angiotensin-aldosterone system, inflammation, oxidative stress, endoplasmic reticulum stress, apoptosis and mitochondrial dysfunction are vital contributors in hypertensive nephropathy (6-9). The renal inflammation, tubular interstitial fibrosis, proteinuria and glomerular sclerosis are valuable markers for evaluation of renal dysfunction in chronic kidney disease (10). Application of angiotensin-converting enzyme inhibitor can reverse hypertension-induced proteinuria and renal damage (11). It is well accepted that antihypertensive therapy can retard the decrease in renal function (12).

Hypertension is recognized as an independent risk factor for chronic renal failure, and renal injury in response to hypertension is reflected by glomerular and tubulointerstitial damages, which is an important determinant for end-stage nephropathy and renal dysfunction (13). Complementary therapies are recommended as promising strategies for prevention and treatment of hypertension and renal damages (14-16). Vaccarin is isolated from Vaccaria segetalis seeds (17), which protects endothelial cells against oxidative stress or high glucose-induced injury $(18,19)$. Bacterial cellulose and bacterial cellulose-vaccarin membranes accelerate wound healing in mice (19). We recently established that intraperitoneal injection of vaccarin ameliorate renovascular hypertension and cardiovascular remodeling in rats (20). However, it is so far unclear whether or not vaccarin can prevent the renal injury secondary to hypertension and, if yes, what were the possible mechanisms. Therefore, we assessed the effects of chronic infusion with vaccarin on renal structure in renovascular hypertensive rats and further attempted to clarify the underlying mechanisms.

\section{Materials and methods}

Animals. Male Sprague-Dawley rats weighing 160-180 g were purchased from Vital River Laboratories Co., Ltd. (Beijing, China). All experiments were conformed to the Guide for 
the Care and Use of Laboratory Animal published by the US National Institutes of Health (NIH publication, 8th edition, 2011). All procedures were complied with the Experimental Animal Care and Use Committee of Jiangnan University. All animals were caged in a temperature-controlled and humidity-controlled room and they were free accessed to standard chow and tap water. All rats were sacrificed under overdose of anesthesia (pentobarbital sodium, peritoneal injection) to minimize discomfort and pain.

Renovascular hypertensive models. The renovascular hypertensive models (two-kidney one-clip, 2K1C) were produced as we previously described $(21,22)$. In short, the rats were anaesthetized by peritoneal injection of pentobarbital sodium $(60 \mathrm{mg} / \mathrm{kg})$ ip. A retroperitoneal flank incision was made to expose the right renal artery, and a U-shaped silver clip of 0.2-mm internal diameter was used to partly occlude the right renal artery under sterile techniques. The sham operated rats (Sham) rats underwent similar surgery without clipping. Two weeks after operation, the $2 \mathrm{~K} 1 \mathrm{C}$ rats received intraperitoneal injection of saline, low dose of vaccarin $(10 \mathrm{mg} / \mathrm{kg}$; Shanghai Shifeng Technology Co., Ltd., Shanghai, China), high dose of vaccarin $(30 \mathrm{mg} / \mathrm{kg})$, captopril (30 mg/kg; Beijing Inoke Co., Ltd., Beijing, China) for 14 days, respectively. The sham operated rats were treated with intraperitoneal injection of saline at the same time. The concentration of vaccarin used in the present study was determined according to our preliminary studies and other previous reports (20,23-25).

Blood pressure and heart rate measurement. The systolic blood pressure (SBP), diastolic blood pressure (DBP), mean arterial pressure (MAP) and heart rate (HR) measured using a a noninvasive computerized tail-cuff IITC blood pressure system (MRBP-2; IITC Life Science Inc., Woodland Hills, CA, USA) according to the manufacturer's instructions. The rats were warmed for $30 \mathrm{~min}$ at $28^{\circ} \mathrm{C}$ in a bag before each measurement to obtain steady pulse level. The SBP, DBP, MAP, and HR were averaged by 10 measurements (26).

Angiotensin (Ang) II levels. The Ang II levels in the right kidney were determined by using an enzyme-linked immunosorbent assay (ELISA) kits (Boster Biological Technology Co., Ltd., Wuhan, China) according to the manufacturer's descriptions. The reacted microtiterplate was ended with stop solution, and the optical density was read at $450 \mathrm{~nm}$ with a microtiter plate reader (STNERGY/H4; BioTek Instruments, Inc., Winooski, VT, USA).

Angiotensin-converting enzyme (ACE) activity assay. The activity of ACE was determined using commercially available kits (Beijing Equation Biological Science and Technology Co., Ltd., Beijing, China) according to the manufacturer's instructions as previously described $(27,28)$. The activity of ACE in the right kidney was expressed in $\mathrm{U} / \mathrm{mg}$ protein.

Histopathology and immunohistochemistry. The rats were sacrificed with overdose of pentobarbital sodium, the right kidney were collected, paraffin-embedded kidney sections $(5 \mu \mathrm{m})$ were stained with Masson's trichrome staining as previous report (29). Immunohistochemistry with angiotensin type 1 (AT1) antibody (Abcam, Cambridge, MA, USA) were performed on the right kidney. The relative AT1 positive cells were quantified with the aid of ImageJ software.

TUNEL assay and ROS detection. The apoptosis of right kidney was assessed by terminal deoxynucleotidyl transferase dUTP nick end labeling (TUNEL) assay. In short, the sectioned kidney was stained using fluorescein-conjugated TUNEL, and the cell nuclei were stained with Hoechst staining. The TUNEL-positive cells were observed a fluorescence microscope (80i; Nikon Corporation, Tokyo, Japan). The apoptotic rate was quantified by counting TUNEL positive cells from 6 random fields and was expressed as a percentage of total cells. The kidney sections were 2',7'-dichlorofluorescein diacetate (DCFH-DA, $10 \mu \mathrm{M}$ ) as previous report $(30,31)$. The fluorescence signals were captured with a multi-detection microplate reader, and quantified with the Image-Pro Plus 6.0 by using the same parameters. The measured fluorescence values were normalized to the fluorescence in control groups.

Real-time quantitative PCR analysis. Total RNA was obtained using TRIzol reagent. Equal RNA levels were reversed transcribed into cDNA using HiScriptQ RT SuperMix for qPCR (Vazyme Biotech Co., Ltd., Nanjing, China). The real-time quantitative PCR was conducted using ChamQ $^{\mathrm{TM}} \mathrm{SYBR}^{\circledR}$ qPCR Master Mix (Vazyme Biotech Co., Ltd.). The relative quantification of gene expression was calculated by using the $2^{-\Delta \Delta C t}$ method (32). The sequences of required primers were listed in the Table I.

Western blot analysis. The protein in right kidney was extracted in RIPA lysis, and was electrophoresed, blotted, and then incubated with indicated primary antibodies at $4{ }^{\circ} \mathrm{C}$ overnight. The blots were then incubated with appropriate secondary horseradish peroxidase (HRP)-conjugated antibodies, the immunoreactive proteins were visualized by enhanced chemiluminescence (Merck KGaA, Darmstadt, Germany).

Reagents. Vaccarin (Fig. 1) was purchased from Shanghai Shifeng Technology Co., Ltd. Cell Meter ${ }^{\mathrm{TM}}$ terminal deoxynucleotidyl transferase-mediated dUTP nick end labeling (TUNEL) apoptosis assay kit was obtained from AAT Bioquest, Inc. (Sunnyvale, CA, USA). DCFH-DA (2',7'-dichlorofluorescin diacetate) were obtained from Sigma-Aldrich (Merck KGaA). The required sequences of paired primers were synthesized by Sangon Biotech Co., Ltd. (Shanghai, China). The primary antibodies against caspase-3, Bcl-2 associated X (Bax), B cell lymphoma (Bcl)-2, AT1, NADPH oxidase (NOX)2, NOX4 and 3NT were purchased from Abcam. Antibodies against tumor necrosis factor- $\alpha$ (TNF- $\alpha$ ), interleukin $1 \beta$ (IL-1 $\beta$ ), and IL-6 and HRP-labeled secondary antibodies were purchased from SANYING Biotechnology Co., Ltd. (Wuhan, China). Antibodies against GAPDH, and the horseradish peroxidase conjugated secondary antibody were purchased from Vazyme Biotech Co., Ltd. Immunohistochemistry kit and diaminobenzidine (DAB) were obtained from Boster Biological Technology Co., Ltd.

Statistical analysis. All results were defined as mean \pm SD. Comparisons within two groups were made by Student's 
Table I. Primers for real-time quantitative PCR analysis in rats.

\begin{tabular}{llll}
\hline Gene & Primer & Sequence & Accession no. \\
\hline Collagen I & Forward & 5'-GAGCCTAACCATCTGGCATCT-3' & NM-053304.1 \\
Collagen III & Forward & 5'-AGAACGAGGTAGTCTTTCAGCAAC-3' & NM-032085.1 \\
& Reverse & 5'-AGATGCTGGTGCTGAGAAG-3' & XM-006245159.1 \\
Fibronectin & Forward & 5'-TGGAAAGAAGTCTGAGGAAGG-3' & NM-017008.4 \\
GAPDH & Reverse & 5'-GTGAAGAACGAGGAGGATGTG-3' & 5'-GTGATGGCGGATGATGTAGC-3' \\
& Forward & 5'-GGAAAGCTGTGGCGTGAT-3' & 5'-AAGGTGGAAGAATGGGAGTT-3' \\
\hline
\end{tabular}

Table II. Body weight, kidney weight at the end of the fourth week.

\begin{tabular}{lccccc}
\hline Variables & Sham & 2K1C-Veh & 2K1C-LDV & 2K1C-HDV & 2K1C-Captopril \\
\hline BW, g & $331.6 \pm 26.1$ & $338.6 \pm 27.2$ & $331.0 \pm 23.3$ & $333.7 \pm 18.7$ & $337.1 \pm 25.6$ \\
RKW, mg & $840.0 \pm 40.7$ & $280.9 \pm 53.6^{\mathrm{a}}$ & $359.0 \pm 99.9$ & $489.0 \pm 177.3^{\mathrm{b}}$ & $812.4 \pm 91.2^{\mathrm{b}}$ \\
LKW, mg & $848.3 \pm 59.1$ & $1497.6 \pm 330.0^{\mathrm{a}}$ & $1166.4 \pm 142.0$ & $991.0 \pm 81.4^{\mathrm{b}}$ & $900.0 \pm 102.8^{\mathrm{b}}$ \\
RKW/BW & $2.5 \pm 0.2$ & $0.8 \pm 0.2^{\mathrm{a}}$ & $1.1 \pm 0.4$ & $1.5 \pm 0.5^{\mathrm{b}}$ & $2.4 \pm 0.2^{\mathrm{b}}$ \\
LKW/BW & $2.6 \pm 0.2$ & $4.4 \pm 0.8^{\mathrm{a}}$ & $3.5 \pm 0.5$ & $3.0 \pm 0.2^{\mathrm{b}}$ & $2.7 \pm 0.3^{\mathrm{b}}$
\end{tabular}

Values are mean \pm SD. 2K1C indicates 2-kidney 1-clip; BW, body weight; RKW, right kidney weight; LKW, left kidney weight; LDV, low dose vaccarin; HDV, high dose vaccarin; and Sham, sham operated. ${ }^{\mathrm{P}}<0.05$ compared with the Sham. ${ }^{\mathrm{b}} \mathrm{P}<0.05$ compared with $2 \mathrm{~K} 1 \mathrm{C}-\mathrm{Veh}$.<smiles>O=c1cc(-c2ccc(O[C@@H]3O[C@H](CO)[C@@H](O)[C@H](O)[C@H]3O)cc2)oc2cc(O)c(C3O[C@H](CO)[C@@H](O)[C@H](O)C3O[C@@H]3OC[C@@H](O)[C@H](O)[C@H]3O)c(O)c12</smiles>

Figure 1. The chemical structure of investigated vaccarin.

t-test. Statistical analysis was performed by ANOVA/Dunnet t-test for multiple group comparisons. The criterion for statistical significance was set at $\mathrm{P}<0.05$.

\section{Results}

General data. There was no significant difference in body weight (BW) between the five groups at the end of the 4th week after $2 \mathrm{~K} 1 \mathrm{C}$ or sham operation. The right kidney weight (RKW) was substantially decreased, but the left kidney weight (LKW) was obviously increased in $2 \mathrm{~K} 1 \mathrm{C}$ rats compared with those in Sham-operated rats, which were reversed by high dose of vaccarin (HDV) and captopril. The lowed RKW/BW ratio and enhanced $\mathrm{LKW} / \mathrm{BW}$ ratio in $2 \mathrm{~K} 1 \mathrm{C}$ rats were restored by both high dose of vaccarin and Captopril (Table II).
Effects of vaccarin on blood pressure and heart rate in $2 \mathrm{~K} 1 \mathrm{C}$ rats. The SBP (Fig. 2A), MAP (Fig. 2B), DBP (Fig. 2C) registered on tail artery in conscious state of $2 \mathrm{~K} 1 \mathrm{C}$ rats were significantly higher than those in Sham rats four weeks after surgery. It is interesting that vaccarin at both low dose and high dose effectively reduced SBP (Fig. 2A), MAP (Fig. 2B), DBP (Fig. 2C) in 2K1C rats, but the high dose of vaccarin caused a similar effect as captopril. There was no significant difference in HR (Fig. 2D) among groups at the end of four weeks.

Effects of vaccarin on renal fibrosis in $2 \mathrm{~K} 1 \mathrm{C}$ rats. Masson's staining showed that the renal fibrosis was significantly elevated in $2 \mathrm{~K} 1 \mathrm{C}$ rats compared with Sham rats, which was consistent with previous findings (33-35). Intraperitoneally administrated with high dose of vaccarin or captopril abrogated the fibrosis in the right kidney in $2 \mathrm{~K} 1 \mathrm{C}$ rats (Fig. $3 \mathrm{~A}$ and $\mathrm{B}$ ), which were further confirmed by the down-regulated markers of fibrosis (collagen-I, collagen-III and fibronectin, Fig. 3C) in the right kidney of $2 \mathrm{~K} 1 \mathrm{C}$ rats.

Effects of vaccarin on renal cell apoptosis in $2 \mathrm{~K} 1 \mathrm{C}$ rats. The $2 \mathrm{~K} 1 \mathrm{C}$ rats had a greater cell apoptotic rate in the right kidney compared with normotensive rats. Compared with rats in the $2 \mathrm{~K} 1 \mathrm{C}$ group, both high dose of vaccarin and captopril suppressed renal cell apoptosis of right kidney, as revealed by TUNEL staining (Fig. 4A and B). The expressions of pro-apoptotic proteins including caspase-3 and Bax were upregulated, whereas anti-apoptosis protein Bcl-2 was decreased in $2 \mathrm{~K} 1 \mathrm{C}$ rats, which were treated by high dose of vaccarin and captopril (Fig. 4C). 

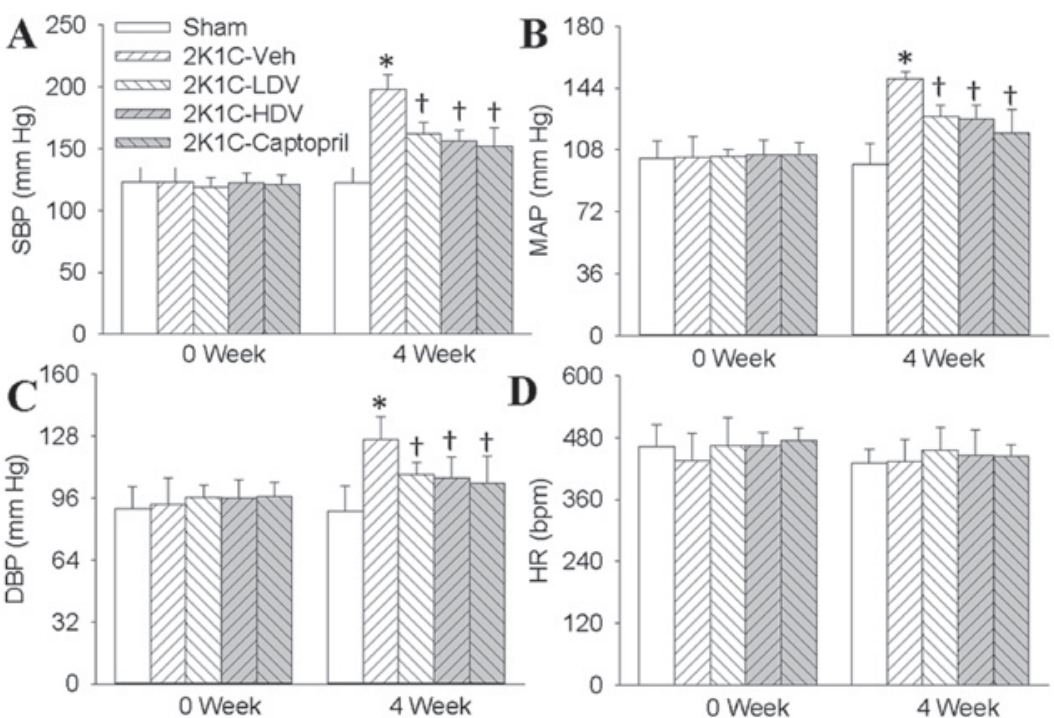

Figure 2. Effects of Vaccarin on the BP and HR in sham-operated or 2K1C rats. The $2 \mathrm{~K} 1 \mathrm{C}$ rats were subjected to intraperitoneal injection low dose of Vaccarin (LDV, $10 \mathrm{mg} / \mathrm{kg} /$ day), high dose of Vaccarin (HDV, $30 \mathrm{mg} / \mathrm{Kg} /$ day) or captopril (30 mg/Kg/day) for 14 days after 2 weeks' operation. The (A) SBP, (B) MAP, (C) DBP and (D) HR were measured with a noninvasive computerized tail-cuff system in conscious rats. Values are expressed as means $\pm \mathrm{SD}$. (n=7 rats/group). ${ }^{*} \mathrm{P}<0.05$ vs. Sham; ${ }^{\dagger} \mathrm{P}<0.05$ vs. $2 \mathrm{~K} 1 \mathrm{C}-$ Veh (vehicle). BP, blood pressure; HR, heart rate; $2 \mathrm{~K} 1 \mathrm{C}$, two-kidney, one clip; DBP, diastolic blood pressure; SBP, systolic blood pressure; MAP, mean arterial pressure.

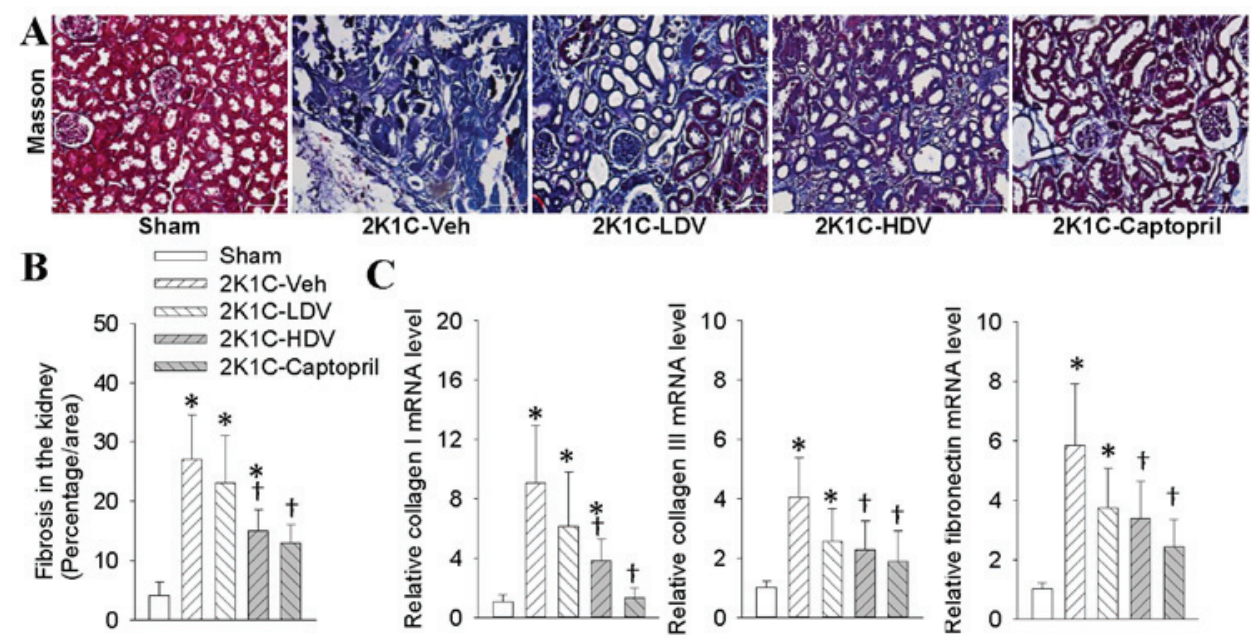

Figure 3. Effects of Vaccarin on the right renal fibrosis in sham-operated or $2 \mathrm{~K} 1 \mathrm{C}$ rats. The $2 \mathrm{~K} 1 \mathrm{C}$ rats were subjected to intraperitoneal injection low dose of Vaccarin (LDV, $10 \mathrm{mg} / \mathrm{kg} / \mathrm{day}$ ), high dose of Vaccarin (HDV, $30 \mathrm{mg} / \mathrm{kg} /$ day) or captopril (30 mg/kg/day) for 14 days after 2 weeks' operation. (A) The sectioned right kidney was collected and stained with Masson's trichrome staining (x200). (B) Bar graph showing quantitative analysis of renal fibrosis. (C) Collagen I, collagen III and fibronectin mRNA expressions in right kidney. Values are expressed as means $\pm \mathrm{SD}$ ( $\mathrm{n}=4$ for each group). ${ }^{*} \mathrm{P}<0.05 \mathrm{vs}$. Sham; ${ }^{\dagger} \mathrm{P}<0.05 \mathrm{vs}$. 2K1C-Veh (vehicle). 2K1C, two-kidney, one clip.

Effects of vaccarin on oxidative stress in $2 \mathrm{KlC}$ rats. Immunofluorescence revealed that $2 \mathrm{~K} 1 \mathrm{C}$ rats exhibited higher superoxide in the right kidney, as determined by fluorescent labeled DCFH-DA in comparison with Sham rats (Fig. 5A and B). When compared with Sham rats, $2 \mathrm{~K} 1 \mathrm{C}$ rats had more NOX2, NOX4, and 3NT protein levels in the right kidney, as measured by western blot analysis (Fig. 5C). Interestingly, chronic application of high dose of vaccarin and captopril prevented the increase in oxidative stress related markers in right kidney of $2 \mathrm{~K} 1 \mathrm{C}$ rats (Fig. 5).

Effects of vaccarin on inflammatory cytokines in $2 \mathrm{KlC}$ rats. We observed that the protein expressions of TNF- $\alpha$, IL- $1 \beta$ and
IL-6 were higher in the right kidney of $2 \mathrm{~K} 1 \mathrm{C}$ rats than those in Sham rats, both high dose of vaccarin and captopril treatment resulted in significant decreases in TNF- $\alpha$, IL-1 $\beta$ and IL-6 protein levels in $2 \mathrm{~K} 1 \mathrm{C}$ rats (Fig. 6).

Effects of vaccarin on Ang II and ATl receptors in $2 \mathrm{KlC}$ rats. Immunohistochemical results revealed that AT1 receptor positive cells were up-regulated in right kidney of $2 \mathrm{~K} 1 \mathrm{C}$ rats in comparison with Sham rats, chronic intraperitoneal infusion of high dose of vaccarin and captopril prevented the AT1 receptor positive cells in renovascular hypertensive rats (Fig. 7A and B). Ang II levels in the right kidney was augmented in $2 \mathrm{~K} 1 \mathrm{C}$ rats, which was prevented by high dose of 

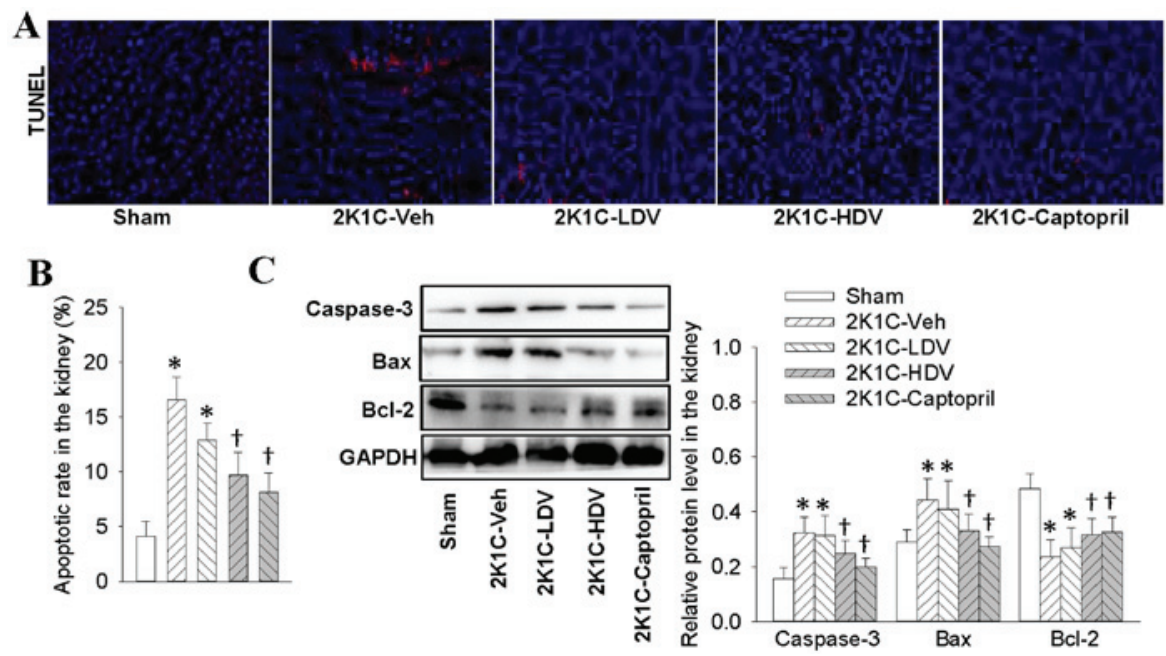

Figure 4. Effects of Vaccarin on the right renal cell apoptosis in sham-operated or $2 \mathrm{~K} 1 \mathrm{C}$ rats. The $2 \mathrm{~K} 1 \mathrm{C}$ rats were subjected to intraperitoneal injection low dose of Vaccarin (LDV, $10 \mathrm{mg} / \mathrm{Kg} /$ day), high dose of Vaccarin (HDV, $30 \mathrm{mg} / \mathrm{kg} /$ day) or captopril $(30 \mathrm{mg} / \mathrm{kg} /$ day) for 14 days after 2 weeks' operation. (A) The sectioned right kidney was collected and renal apoptosis as measured or TUNEL staining (x200). (B) The numbers of TUNEL-positive cells were quantified. (C) Expressions of caspase-3, Bax and Bcl-2. Values are expressed as means $\pm \mathrm{SD}$ ( $\mathrm{n}=4$ for each group). ${ }^{*} \mathrm{P}<0.05$ vs. Sham; ${ }^{\dagger} \mathrm{P}<0.05$ vs. $2 \mathrm{~K} 1 \mathrm{C}-\mathrm{Veh}$ (vehicle) 2K1C, two-kidney, one clip; TdT, terminal deoxynucleotidyl transferase; TUNEL, terminal deoxynucleotidyl transferase dUTP nick end labeling; Bcl, B cell lymphoma.

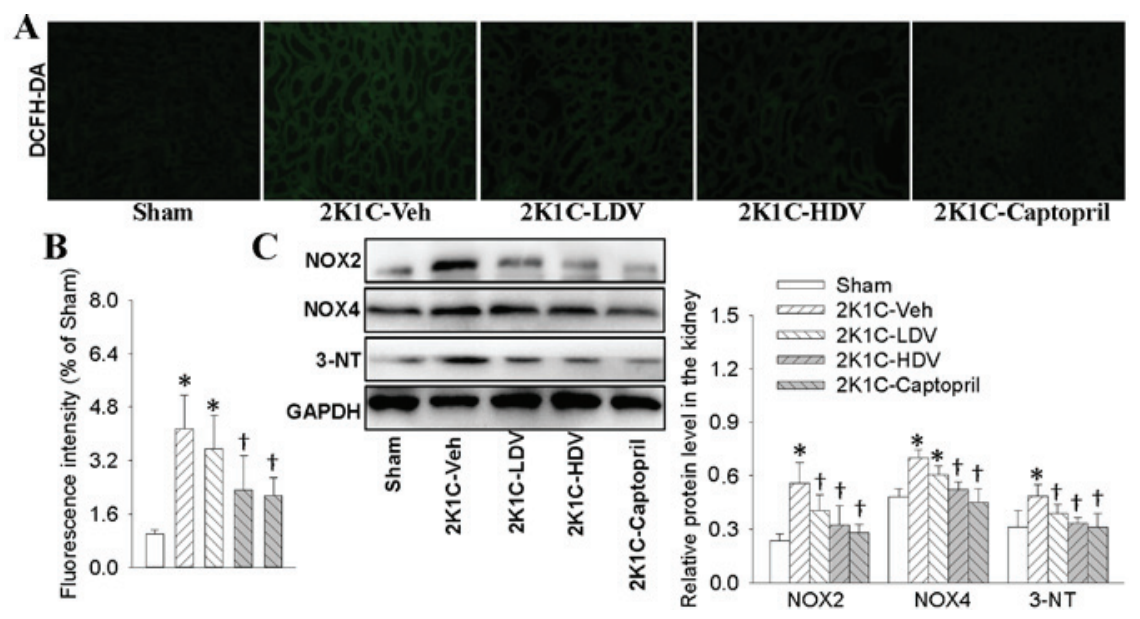

Figure 5. Effects of Vaccarin on the oxidative stress in right kidney in sham-operated or $2 \mathrm{~K} 1 \mathrm{C}$ rats. The $2 \mathrm{~K} 1 \mathrm{C}$ rats were subjected to intraperitoneal injection low dose of Vaccarin (LDV, $10 \mathrm{mg} / \mathrm{kg} / \mathrm{day}$ ), high dose of Vaccarin (HDV, $30 \mathrm{mg} / \mathrm{kg} / \mathrm{day}$ ) or captopril (30 mg/kg/day) for 14 days after 2 weeks' operation. (A) The sectioned right kidney was collected and the ROS levels measured by DCFH-DA (x200). (B) The fluorescence density were quantified and normalized to the control. (C) Expressions of NOX-2, NOX-4 and 3-NT. Values are expressed as means $\pm \mathrm{SD}$ ( $\mathrm{n}=4$ for each group). ${ }^{*} \mathrm{P}<0.05$ vs. Sham; ${ }^{\dagger} \mathrm{P}<0.05$ vs. $2 \mathrm{~K} 1 \mathrm{C}-\mathrm{Veh}$ (vehicle). 2K1C, two-kidney, one clip; NOX, NADPH oxidase.
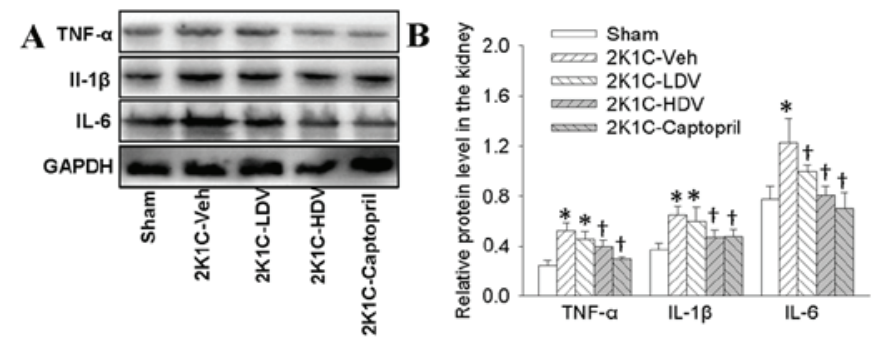

Figure 6. Effects of Vaccarin on the inflammatory response in right kidney in sham-operated or $2 \mathrm{~K} 1 \mathrm{C}$ rats. The $2 \mathrm{~K} 1 \mathrm{C}$ rats were subjected to intraperitoneal injection low dose of Vaccarin (LDV, $10 \mathrm{mg} / \mathrm{kg} / \mathrm{day}$ ), high dose of Vaccarin (HDV, $30 \mathrm{mg} / \mathrm{kg} /$ day) or captopril (30 mg/kg/day) for 14 days after 2 weeks operation. (A) Representative blots showing the protein levels of TNF- $\alpha$, IL-1 $\beta$ and IL-6. (B) Quantitative analysis of TNF- $\alpha$, IL-1 $\beta$ and IL-6. Values are expressed as means $\pm \mathrm{SD}$ ( $\mathrm{n}=4$ for each group). ${ }^{*} \mathrm{P}<0.05$ vs. Sham; ${ }^{\dagger} \mathrm{P}<0.05$ vs. $2 \mathrm{~K} 1 \mathrm{C}-\mathrm{Veh}$ (vehicle). $2 \mathrm{~K} 1 \mathrm{C}$, two-kidney, one clip; IL-1 $\beta$, interleukin $1 \beta$; TNF- $\alpha$, tumor necrosis factor- $\alpha$. vaccarin and captopril (Fig. 7C). Our results also showed that the ACE activity in the right kidney was higher in $2 \mathrm{~K} 1 \mathrm{C}$ rats than that in Sham rats. Similarly, vaccarin treatment attenuated the changes in the ACE activity (Fig. 7D). Western blot further demonstrated that high dose of vaccarin and captopril treatment attenuated the upregulated AT1 protein expressions in $2 \mathrm{~K} 1 \mathrm{C}$ rats (Fig. $7 \mathrm{E}$ and $\mathrm{F}$ ).

\section{Discussion}

Chronic kidney disease is a prevalent medical condition with increased morbidity worldwide (36). Hypertension is an important pathogenic factor that participates in the deterioration of renal function, and many patents with hypertension eventually develop chronic kidney disease (37). Hypertension is one of the 


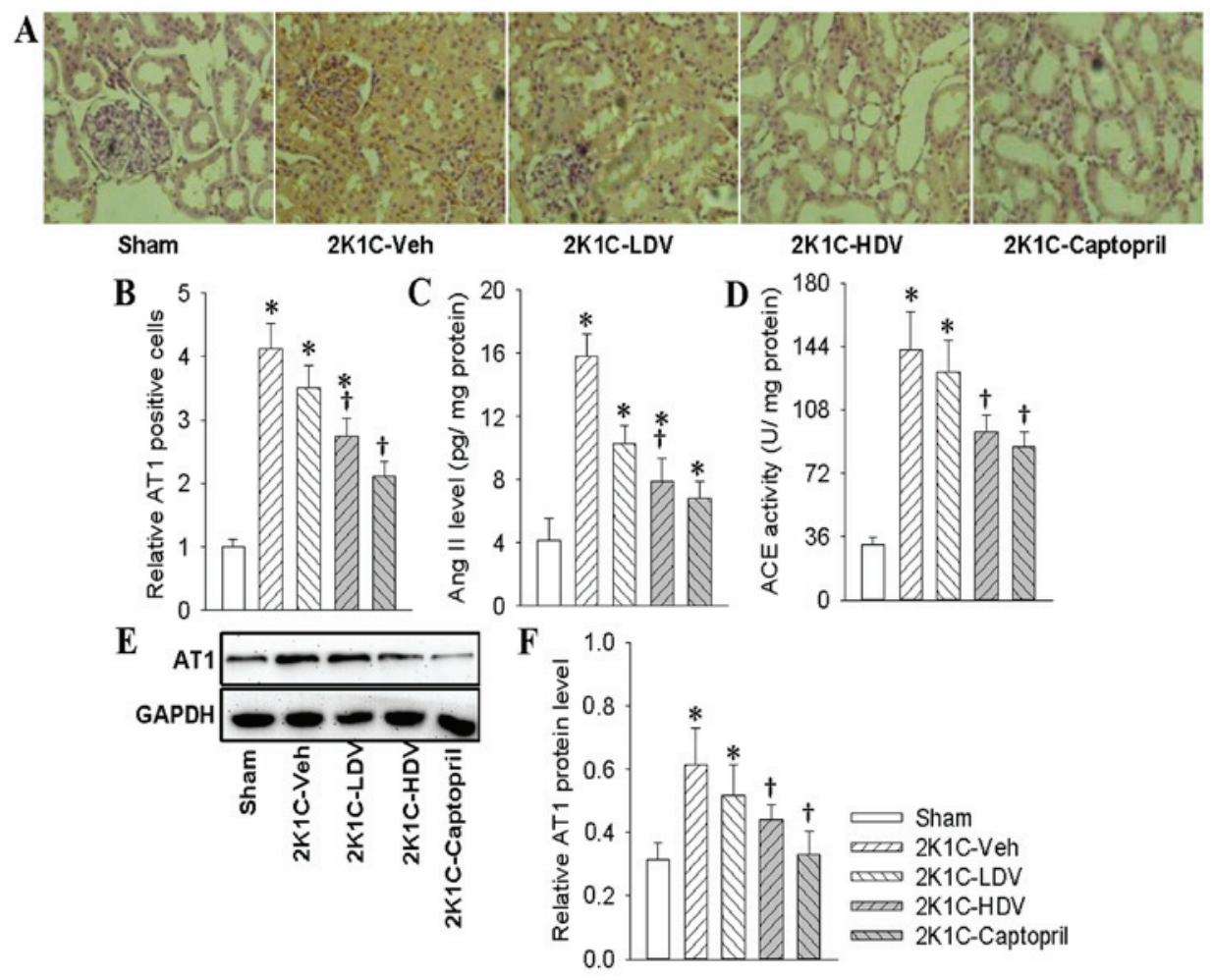

Figure 7. Effects of Vaccarin on the Ang II and AT1 expressions in right kidney in sham-operated (Sham) or $2 \mathrm{~K} 1 \mathrm{C}$ rats. The $2 \mathrm{~K} 1 \mathrm{C}$ rats were subjected to intraperitoneal injection low dose of Vaccarin (LDV, $10 \mathrm{mg} / \mathrm{kg} / \mathrm{day}$ ), high dose of Vaccarin (HDV, $30 \mathrm{mg} / \mathrm{kg} / \mathrm{day}$ ) or captopril (30 mg/kg/day) for $14 \mathrm{days}$ after 2 weeks' operation. (A) The AT1 immunoreactivity in right kidney of Sham rats and 2K1C rats (x400). (B) Bar graph showing the relative cells with AT1 immunoreactivity in right kidney of Sham and 2K1C rats. (C) The Ang II levels were measured with ELISA. (D) ACE activities in right kidney were measured. (E and F) AT1 protein expressions were measured by western blot analysis. Values are expressed as means $\pm \mathrm{SD}$ ( $\mathrm{n}=7$ for each group). ${ }^{*} \mathrm{P}<0.05$ vs. Sham; ${ }^{\dagger} \mathrm{P}<0.05$ vs. $2 \mathrm{~K} 1 \mathrm{C}-$ Veh (vehicle). Ang II, angiotensin II; $2 \mathrm{~K} 1 \mathrm{C}$, two-kidney, one clip; ACE, angiotensin converting enzyme; AT1, angiotensin type 1.

most common comorbidities in patients with chronic kidney disease, more than $85 \%$ of patients with stage 3-5 chronic kidney disease are complicated with hypertension (38). Vaccarin is believed to play a protective role in endothelial dysfunction. However, the therapeutic effects of vaccarin on hypertensive kidney damage have not been researched. In this study, we demonstrated for the first time that vaccarin not only normalized blood pressure, but also attenuates renal fibrosis, renal cell apoptosis, oxidative stress, inflammatory response, Ang II and AT1 receptors expressions in $2 \mathrm{~K} 1 \mathrm{C}$ renovascular hypertensive rats. These results suggested that vaccarin exerted antioxidant, antifibrotic, antiapoptotic and anti-inflammatory effects in hypertensive renal injury associated with downregulation of Ang II/AT1 system in 2K1C rats.

Renal fibrosis is one of the characteristics in end-stage renal failure, which may result from hypertension and diabetic nephropathy (39). Progressive destructive function of kidney is associated with tubular interstitial fibrosis in hypertension. It is reported that gene deletion of growth arrest-specific protein 6 lowed renal inflammation and renal fibrosis (40). The renal apoptosis is enhanced in the right kidney in $2 \mathrm{~K} 1 \mathrm{C}$ rats $(41,42)$. Administration of angiotensin- (1-7) improves glomerular tuft volume and decreases tubular apoptosis in Akita mice (43). In this study, our data showed that vaccarin caused reductions in collagen synthesis in right kidney of $2 \mathrm{~K} 1 \mathrm{C}$ rats. Furthermore, the increased renal cell apoptosis rate evidenced by TUNEL staining, augmented pro-apoptotic proteins including caspase-3, Bax, and downregulated anti-apoptosis protein
Bcl-2 in $2 \mathrm{~K} 1 \mathrm{C}$ rats were treated by vaccarin treatment. These results suggested that vaccarin may be beneficial to kidney via targeted inhibition of renal fibrosis and apoptosis.

Oxidative stress plays a key role in renal dysfunction and hypertension (44-46). Excessive ROS production response to oxidative stress may affect all types of intrinsic kidney cells (47). Oxidative stress leads to podocyte apoptosis and subsequent segmental glomerulosclerosis, resulting in kidney damage in hypertension (48). In addition, oxidative stress also induces the myofibroblasts accumulation in the kidney and remodeling of the extracellular matrix of the tubulointerstitium (48). NOXs are major sources of ROS production within the kidney (49). It has been established that the increased levels of medullary NOX2 and tissue ROS in Dahl salt-sensitive (SS) hypertensive rats are alleviated by chronic medullary interstitial infusions of NOX inhibitor apocynin (50). NOX4 is also abundantly expressed in the kidney, and knock out of NOX4 blocked oxidative stress, protein matrix production, and kidney injury in the kidney of SS rat (51). 3-NT is taken as a marker for peroxynitrite-evoked oxidative stress (52). In the present study, we showed that the ROS, NOX2, NOX4 and $3 \mathrm{NT}$ expressions were significantly increased in the $2 \mathrm{~K} 1 \mathrm{C}$ rats compared to those in the Sham rats, However, these effects were decreased following vaccarin treatment. These results indicated that vaccarin exhibited an obvious improvement in oxidative stress injury in $2 \mathrm{~K} 1 \mathrm{C}$ rats.

Inflammation is a major player in hypertension-associated of kidney disease. Oxidative stress and inflammation in kidney 
may synergistically contribute to the pathogenesis of renal injury (53). The glomerular microinflammation is occurred in persistent systemic hypertension state (54). Treatment with statin abated the renal inflammation and podocyte damage in DOCA-salt hypertension rats (55). Pharmacological inhibition of galectin-3 reduces inflammatory cytokines, and extracellular matrix proteinases, and renal fibrosis in TGR (mREN)27 (REN2) hypertensive rats (4). The levels of TNF- $\alpha$ are upregulated in the kidney of Ang II-dependent hypertensive models and associated kidney disease (56). Anti-inflammatory therapy may be promising therapeutic strategy for hypertensive kidney damage. Our results showed that vaccarin treatment decreased the expressions of inflammatory mediators including TNF- $\alpha$, IL- $1 \beta$ and IL- 6 in the right kidney of $2 \mathrm{~K} 1 \mathrm{C}$ rats. These data hinted that vaccarin may act anti-inflammatory effects to protect kidney from injury in $2 \mathrm{~K} 1 \mathrm{C}$ renovascular hypertensive rats.

The renin-angiotensin system (RAS) has a critical role in mammalian homeostasis (57). The RAS family consists of angiotensinogen, renin, angiotensin-converting enzyme, Ang II and AT1 receptors, and other main components, among which, Ang II and AT1 receptors displayed powerful effects on kidney damage by a variety of mechanisms in chronic kidney disease (58). Mounting evidence demonstrates that local intrarenal RAS activation may directly dictate kidney damage (59). Ang II binds to AT1 receptors to stimulate generation of reactive oxygen species, and renal inflammation, which are synergistically for the initiation and progression of renal damage in hypertension (60). It has been established that Ang II infusion leads to hypertension and renal fibrosis in mice or rats (61). The abnormal formation of Ang II triggers systemic hypertension and renal damages associated with activation of fibrogenic, pro-inflammatory and apoptotic pathways (6). AT1 receptor antagonist Losartan is used to treat hypertension and targeted renal damage. Our study showed that the elevated SBP, MAP, DBP, Ang II and AT1 receptor levels were increased in $2 \mathrm{~K} 1 \mathrm{C}$ rats in comparison with Sham rats, which were partially abolished by vaccarin in $2 \mathrm{~K} 1 \mathrm{C}$ rats. These results implied that vaccarin may counteract Ang II/ AT1 system in the kidney to impede renal fibrosis, apoptosis, ROS generation and inflammatory response, thus protecting against hypertension-related renal damages.

Taken together, our results provided for the first time that vaccarin protected the $2 \mathrm{~K} 1 \mathrm{C}$ rats from renal oxidative stress, renal inflammatory response, renal injury and hypertension. Vaccarin may be employed as a complementary and alternative pharmacological agent that ameliorates hypertension and renal function detriment in subjects who were predisposed to hypertension. Nevertheless, as a natural product, high dose of vaccarin at least showed the similar protective effects on hypertension and cardiovascular remodeling as captopril from animal research. In addition, such ACE inhibitors including captopril have clinical side effects including cough, angioneurotic edema, and deleterious effects during pregnancy $(62,63)$. In terms of vaccarin, there are still many unsolved problems, such as whether vaccarin can be employed as a prescription for hypertension in hypertensive patients, whether combination of vaccarin with classical antihypertensive drugs exerted better effect and less adverse reactions on hypertension. Further studies are needed regarding the more detailed role of vaccarin in hypertension and cardiovascular remodeling.

\section{Acknowledgements}

This work was supported by Fundamental Research Funds for the Central Universities (JUSRP11745), Public Health Research Center at Jiangnan University (grant no. JUPH201504), Jiangsu Natural Science Foundation of China (grant no. BK20170179) and Project funded by China Postdoctoral Science Foundation (2017M611688).

\section{References}

1. Wang Z, do Carmo JM, Aberdein N, Zhou X, Williams JM, da Silva AA and Hall JE: Synergistic interaction of hypertension and diabetes in promoting kidney injury and the role of endoplasmic reticulum stress. Hypertension 69: 879-891, 2017.

2. Retnakaran R, Cull CA, Thorne KI, Adler AI and Holman RR; UKPDS Study Group: Risk factors for renal dysfunction in type 2 diabetes: U.K. Diabetes 55: 1832-1839, 2006.

3. Janssen U, Riley SG, Vassiliadou A, Floege J and Phillips AO: Hypertension superimposed on type II diabetes in Goto Kakizaki rats induces progressive nephropathy. Kidney Int 63: 2162-2170, 2003.

4. Frenay AR, Yu L, van der Velde AR, Vreeswijk-Baudoin I, López-Andrés N, van Goor H, Silljé HH, Ruifrok WP and de Boer RA: Pharmacological inhibition of galectin-3 protects against hypertensive nephropathy. Am J Physiol Renal Physiol 308: F500-F509, 2015.

5. Becker GJ and Hewitson TD: The role of tubulointerstitial injury in chronic renal failure. Curr Opin Nephrol Hypertens 9: 133-138, 2000.

6. Padda RS, Shi Y,Lo CS, Zhang SL and Chan JS: Angiotensin-(1-7): A novel peptide to treat hypertension and nephropathy in diabetes? J Diabetes Metab 6, 2015.

7. Miloradović Z, Ivanov M, Jovović D, Karanović D, Vajić UJ, Marković-Lipkovski J, Mihailović-Stanojević N and Milanović JG: Angiotensin 2 type 1 receptor blockade different affects postishemic kidney injury in normotensive and hypertensive rats. J Physiol Biochem 72: 813-820, 2016.

8. Gai Z, Gui T, Hiller C and Kullak-Ublick GA: Farnesoid X receptor protects against kidney injury in uninephrectomized obese mice. J Biol Chem 291: 2397-2411, 2016.

9. Linkermann A, Chen G, Dong G, Kunzendorf U, Krautwald S and Dong Z: Regulated cell death in AKI. J Am Soc Nephrol 25: 2689-2701, 2014.

10. Granger JP: An emerging role for inflammatory cytokines in hypertension. Am J Physiol Heart Circ Physiol 290: H923-H924, 2006.

11. Brouwers FP, de Boer RA, van der Harst P, Struck J, de Jong PE, de Zeeuw D, Gans RO, Gansevoort RT, Hillege HL, van Gilst WH and Bakker SJ: Influence of age on the prognostic value of mid-regional pro-adrenomedullin in the general population. Heart 98: 1348-1353, 2012.

12. Peterson JC, Adler S, Burkart JM, Greene T, Hebert LA, Hunsicker LG, King AJ, Klahr S, Massry SG and Seifter JL: Blood pressure control, proteinuria, and the progression of renal disease. The Modification of Diet in Renal Disease Study. Ann Intern Med 123: 754-762, 1995.

13. Crews DC, Plantinga LC, Miller ER III, Saran R, Hedgeman E, Saydah SH, Williams DE and Powe NR; Centers for Disease Control and Prevention Chronic Kidney Disease Surveillance Team: Prevalence of chronic kidney disease in persons with undiagnosed or prehypertension in the United States. Hypertension 55: 1102-1109, 2010.

14. Veeramani C, Al-Numair KS, Chandramohan G, Alsaif MA and Pugalendi KV: Antihyperlipidemic effect of Melothria maderaspatana leaf extracts on DOCA-salt induced hypertensive rats. Asian Pac J Trop Med 5: 434-439, 2012.

15. Yu D, Shi M, Bao J, Yu X, Li Y and Liu W: Genipin ameliorates hypertension-induced renal damage via the angiotensin II-TLR/MyD88/MAPK pathway. Fitoterapia 112: 244-253, 2016. 
16. Liu XP, Pang YJ, Zhu WW, Zhao TT, Zheng M, Wang YB, Sun ZJ and Sun SJ: Benazepril, an angiotensin-converting enzyme inhibitor, alleviates renal injury in spontaneously hypertensive rats by inhibiting advanced glycation end-product-mediated pathways. Clin Exp Pharmacol Physiol 36: 287-296, 2009.

17. Balsevich JJ, Ramirez-Erosa I, Hickie RA, Dunlop DM, Bishop GG and Deibert LK: Antiproliferative activity of Saponaria vaccaria constituents and related compounds. Fitoterapia 83: 170-181, 2012

18. Xie F, Cai W, Liu Y, Li Y, Du B, Feng L and Qiu L: Vaccarin attenuates the human EA.hy926 endothelial cell oxidative stress injury through inhibition of Notch signaling. Int J Mol Med 35: 135-142, 2015

19. Qiu Y, Qiu L, Cui J and Wei Q: Bacterial cellulose and bacterial cellulose-vaccarin membranes for wound healing. Mater Sci Eng C Mater Biol Appl 59: 303-309, 2016.

20. Zhu X, Zhou Z, Zhang Q, Cai W, Zhou Y, Sun H and Qiu L: Vaccarin administration ameliorates hypertension and cardiovascular remodeling in renovascular hypertensive rats. J Cell Biochem Jul 6: 2017 (Epub ahead of print).

21. Zhang LL, Ding L, Zhang F, Gao R, Chen Q, Li YH, Kang YM and Zhu GQ: Salusin- $\beta$ in rostral ventrolateral medulla increases sympathetic outflow and blood pressure via superoxide anions in hypertensive rats. J Hypertens 32: 1059-1067, 2014.

22. Zhou YB, Sun HJ, Chen D, Liu TY, Han Y, Wang JJ, Tang CS Kang YM and Zhu GQ: Intermedin in paraventricular nucleus attenuates sympathetic activity and blood pressure via nitric oxide in hypertensive rats. Hypertension 63: 330-337, 2014.

23. Zhang NB, Huang ZG, Cui WD and Ding BP: Effects of puerarin on expression of cardiac Smad3 and Smad7 mRNA in spontaneously hypertensive rat. J Ethnopharmacol 138: 737-740, 2011.

24. Ghazi-Khansari M, Mohammadi-Karakani A, Sotoudeh M, Mokhtary P, Pour-Esmaeil E and Maghsoud S: Antifibrotic effect of captopril and enalapril on paraquat-induced lung fibrosis in rats. J Appl Toxicol 27: 342-349, 2007.

25. Wu JB, Zhou Y, Liang CL, Zhang XJ, Lai JM, Ye SF, Ouyang H, Lin J and Zhou JY: Cyclovirobuxinum D alleviates cardiac hypertrophy in hyperthyroid rats by preventing apoptosis of cardiac cells and inhibiting the p38 mitogen-activated protein kinase signaling pathway. Chin J Integr Med: Mar 17, 2016 (Epub ahead of print).

26. Chen WW, Sun HJ, Zhang F, Zhou YB, Xiong XQ, Wang JJ and Zhu GQ: Salusin- $\beta$ in paraventricular nucleus increases blood pressure and sympathetic outflow via vasopressin in hypertensive rats. Cardiovasc Res 98: 344-351, 2013.

27. Wang C, Liu X, Tang Y, Peng H, Ye Z, Zhang J, Tang H and Lou T: Medium from mesangial cells incubated with aggregated IgA1 from IgA nephropathy patients reduces podocyte adhesion through activation of the renin angiotensin system. Swiss Med Wkly 141: w13304, 2011.

28. Takai S, Jin D, Chen H, Li W, Yamamoto H, Yamanishi K, Miyazaki M, Higashino $H$, Yamanishi $H$ and Okamura $H$ Chymase inhibition improves vascular dysfunction and survival in stroke-prone spontaneously hypertensive rats. J Hypertens 32: $1637-1649,2014$

29. Sun HJ, Liu TY, Zhang F, Xiong XQ, Wang JJ, Chen Q, Li YH, Kang YM, Zhou YB, Han Y, et al: Salusin- $\beta$ contributes to vascular remodeling associated with hypertension via promoting vascular smooth muscle cell proliferation and vascular fibrosis. Biochim Biophys Acta 1852: 1709-1718, 2015.

30. Sun HJ, Zhao MX, Ren XS, Liu TY, Chen Q, Li YH, Kang YM, Wang JJ and Zhu GQ: Salusin- $\beta$ promotes vascular smooth muscle cell migration and intimal hyperplasia after vascular injury via ROS/NFאB/MMP-9 pathway. Antioxid Redox Signal 24: 1045-1057, 2016.

31. Kim MJ, Ryu JC, Kwon Y, Lee S, Bae YS, Yoon JH and Ryu JH: Dual oxidase 2 in lung epithelia is essential for hyperoxia-induced acute lung injury in mice. Antioxid Redox Signal 21: 1803-1818, 2014.

32. Sun HJ, Chen D, Han Y, Zhou YB, Wang JJ, Chen Q, Li YH, Gao XY, Kang YM and Zhu GQ: Relaxin in paraventricular nucleus contributes to sympathetic overdrive and hypertension via PI3K-Akt pathway. Neuropharmacology 103: 247-256, 2016.

33. Cuevas CA, Tapia-Rojas C, Cespedes C, Inestrosa NC and Vio CP: $\beta$-Catenin-dependent signaling pathway contributes to renal fibrosis in hypertensive rats. Biomed Res Int 2015: 726012, 2015.

34. Wang Z, Zhu Q, Li PL, Dhaduk R, Zhang F, Gehr TW and Li N: Silencing of hypoxia-inducible factor-1 $\alpha$ gene attenuates chronic ischemic renal injury in two-kidney, one-clip rats. Am J Physiol Renal Physiol 306: F1236-F1242, 2014.
35. Cavallari LH, Fashingbauer LA, Camp JR, King ST and Geenen DL: Hypertension-induced renal fibrosis and spironolactone response vary by rat strain and mineralocorticoid receptor gene expression. J Renin Angiotensin Aldosterone Syst 9: $146-153,2008$

36. Go AS, Chertow GM, Fan D, McCulloch CE and Hsu CY: Chronic kidney disease and the risks of death, cardiovascular events, and hospitalization. N Engl J Med 351: 1296-1305, 2004.

37. Whitman IR, Feldman HI and Deo R: CKD and sudden cardiac death: Epidemiology, mechanisms, and therapeutic approaches. J Am Soc Nephrol 23: 1929-1939, 2012.

38. Muntner P, Anderson A, Charleston J, Chen Z, Ford V, Makos G, O'Connor A, Perumal K, Rahman M, Steigerwalt S, et al: Hypertension awareness, treatment, and control in adults with CKD: Results from the chronic renal insufficiency cohort (CRIC) Study. Am J Kidney Dis 55: 441-451, 2010.

39. Piret SE, Olinger E, Reed AA, Nesbit MA, Hough TA, Bentley L, Devuyst O, Cox RD and Thakker RV: Mouse model for inherited renal fibrosis associated with endoplasmic reticulum stress. Dis Model Mech 10: 773-786, 2017

40. Park JK, Theuer S, Kirsch T, Lindschau C, Klinge U, Heuser A, Plehm R, Todiras M, Carmeliet P, Haller H, et al: Growth arrest specific protein 6 participates in DOCA-induced target-organ damage. Hypertension 54: 359-364, 2009.

41. Campagnaro BP, Tonini CL, Doche LM, Nogueira BV, Vasquez EC and Meyrelles SS: Renovascular hypertension leads to DNA damage and apoptosis in bone marrow cells. DNA Cell Biol 32: 458-466, 2013.

42. Li P, Huang PP, Yang Y, Liu C, Lu Y, Wang F, Sun W and Kong XQ: Renal sympathetic denervation attenuates hypertension and vascular remodeling in renovascular hypertensive rats. J Appl Physiol (1985) 122: 121-129, 2017.

43. Shi Y,Lo CS, Padda R, Abdo S, Chenier I, Filep JG, Ingelfinger JR, Zhang SL and Chan JS: Angiotensin-(1-7) prevents systemic hypertension, attenuates oxidative stress and tubulointerstitial fibrosis, and normalizes renal angiotensin-converting enzyme 2 and Mas receptor expression in diabetic mice. Clin Sci (Lond) 128: 649-663, 2015

44. Cowley AW Jr: Renal medullary oxidative stress, pressure-natriuresis, and hypertension. Hypertension 52: 777-786, 2008.

45. Araujo M and Wilcox CS: Oxidative stress in hypertension: Role of the kidney. Antioxid Redox Signal 20: 74-101, 2014.

46. Manning RD Jr, Tian N and Meng S: Oxidative stress and antioxidant treatment in hypertension and the associated renal damage. Am J Nephrol 25: 311-317, 2005.

47. Daehn I, Casalena G, Zhang T, Shi S, Fenninger F, Barasch N, Yu L, D'Agati V, Schlondorff D, Kriz W, et al: Endothelial mitochondrial oxidative stress determines podocyte depletion in segmental glomerulosclerosis. J Clin Invest 124: 1608-1621, 2014.

48. Eddy AA: Molecular basis of renal fibrosis. Pediatr Nephrol 15: 290-301, 2000

49. Lassegue B, San Martin A and Griendling KK: Biochemistry, physiology, and pathophysiology of NADPH oxidases in the cardiovascular system. Circ Res 110: 1364-1390, 2012.

50. Taylor NE, Glocka P, Liang M and Cowley AW Jr: NADPH oxidase in the renal medulla causes oxidative stress and contributes to salt-sensitive hypertension in Dahl S rats. Hypertension 47: 692-698, 2006

51. Cowley AW Jr, Yang C, Zheleznova NN, Staruschenko A, Kurth T, Rein L, Kumar V, Sadovnikov K, Dayton A, Hoffman M, et al: Evidence of the importance of Nox4 in production of hypertension in Dahl salt-sensitive rats. Hypertension 67: 440-450, 2016

52. Wu N, Shen H, Liu H, Wang Y, Bai Y and Han P: Acute blood glucose fluctuation enhances rat aorta endothelial cell apoptosis, oxidative stress and pro-inflammatory cytokine expression in vivo. Cardiovasc Diabetol 15: 109, 2016.

53. Ruiz S, Pergola PE, Zager RA and Vaziri ND: Targeting the transcription factor Nrf2 to ameliorate oxidative stress and inflammation in chronic kidney disease. Kidney Int 83: 1029-1041, 2013

54. Meguid El Nahas A and Bello AK: Chronic kidney disease: The global challenge. Lancet 365: 331-340, 2005.

55. Hartner A, Klanke B, Cordasic N, Amann K, Schmieder RE, Veelken $R$ and Hilgers KF: Statin treatment reduces glomerular inflammation and podocyte damage in rat deoxycorticosterone-acetate-salt hypertension. J Hypertens 27: 376-385, 2009. 
56. Zhang J, Patel MB, Griffiths R, Mao A, Song YS, Karlovich NS, Sparks MA, Jin H, Wu M, Lin EE and Crowley SD: Tumor necrosis factor- $\alpha$ produced in the kidney contributes to angiotensin II-dependent hypertension. Hypertension 64: 1275-1281, 2014.

57. Rincón J, Correia D, Arcaya JL, Finol E, Fernández A, Pérez M, Yaguas K, Talavera E, Chávez M, Summer R and Romero F: Role of Angiotensin II type 1 receptor on renal NAD(P)H oxidase, oxidative stress and inflammation in nitric oxide inhibition induced-hypertension. Life Sci 124: 81-90, 2015.

58. Zhou L, Mo H, Miao J, Zhou D, Tan RJ, Hou FF and Liu Y: Klotho ameliorates kidney injury and fibrosis and normalizes blood pressure by targeting the renin-angiotensin system. Am J Pathol 185: 3211-3223, 2015 .

59. Crowley SD, Gurley SB, Herrera MJ, Ruiz P, Griffiths R, Kumar AP, Kim HS, Smithies O, Le TH and Coffman TM: Angiotensin II causes hypertension and cardiac hypertrophy through its receptors in the kidney. Proc Natl Acad Sci USA 103: 17985-17990, 2006
60. Ruggenenti P, Cravedi P and Remuzzi G: Mechanisms and treatment of CKD. J Am Soc Nephrol 23: 1917-1928, 2012.

61. Zhang JS, Zhang YL, Wang HX, Xia YL, Wang L, Jiang YN, $\mathrm{Li} \mathrm{HH}$ and Liu Y: Identification of genes related to the early stage of Angiotensin II-induced acute renal injury by microarray and integrated gene network analysis. Cell Physiol Biochem 34: 1137-1151, 2014.

62. Kuriyama S: The relation between green tea consumption and cardiovascular disease as evidenced by epidemiological studies. J Nutr 138: 1548S-1553S, 2008.

63. Israili ZH and Hall WD: Cough and angioneurotic edema associated with angiotensin-converting enzyme inhibitor therapy. A review of the literature and pathophysiology. Ann Intern Med 117: 234-242, 1992. International (CC BY-NC-ND 4.0) License. 